\title{
THE CASE NOTES OF THE NATIONAL HOSPITAL FOR THE PARALYSED AND EPILEPTIC, QUEEN SQUARE, LONDON, BEFORE 1900*
}

\author{
BY
}

\section{RICHARD A. HUNTER and L. J. HURWITZ}

The case notes of the National Hospital present a unique opportunity of following the development of clinical neurology in the second half of the nineteenth century since for much of this time it was the only hospital specializing in neurological diseases. It is owing to the foresight of the hospital's early physicians and administrators that from 1863three years after its opening - the in-patient records are preserved complete and they give a vivid picture of clinical neurology as it was practised and developed during those early years.

The earliest case book covering the period 1863-67 consists simply of the patient's history, a note of obvious physical signs, medicines given, and diagnosis. Figures 1(a) and (b) shows the notes of a patient with aphasia and left hemiplegia written in 1865. Dr. Hughlings Jackson's interest in this combination is apparent from his pencilled request to see the patient.

From 1867 the notes became more substantial and consisted of an out-patient sheet bound with the in-patient notes. The in-patients' notes were now made up of a front sheet giving personal details, dates of admission and discharge, duration of illness, result of treatment, diagnosis, and the name of the physician under whose care the patient was; later the names of the house physician and clinical clerk were also recorded. There follow continuation sheets, treatment card, fit charts in epileptic cases, in febrile cases temperature charts which included recordings of pulse, respiration, weight, and analysis of urine; not infrequently sensory and perimetry charts, clinical and post-mortem drawings and photographs were also included. Occasionally, correspondence from referring doctors or other consultants was preserved.

Figure 2 shows a photograph in the case notes of a patient of Dr. Thomas Buzzard in 1875 diagnosed as hysterical ptosis. Note the absence of compensatory contraction of the frontalis muscle on the

*This paper was read at the National Hospital centenary celebrations on June 22, 1960. affected side, which helps to distinguish the condition from this cranial nerve palsy. Incidentally, there is also a photograph of her normal appearance after treatment.

At the end of a year each physician's notes were bound in a volume in alphabetical order to which was prefixed an index of patients' names and diagnoses. In 1880 , a separate diagnostic card index was established, and as the number of patients in the hospital increased, the notes of men and women were bound separately. These volumes are now arranged on shelves around the walls of the registrat's room in the Out-patient Department, which is in

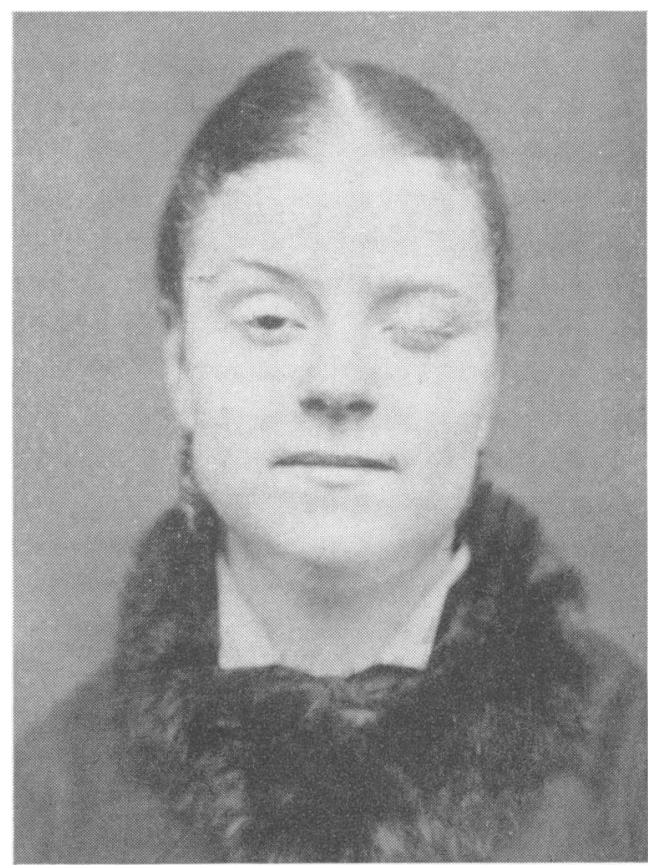

Fig. 2.-Photograph of a patient of Dr. Thomas Buzzard illustrating hysterical ptosis by the absence of compensatory contraction of the frontalis muscle, 1875 . 


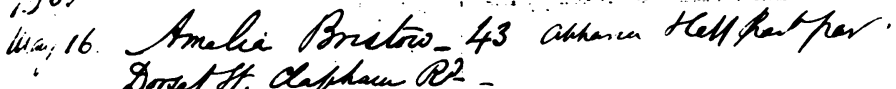

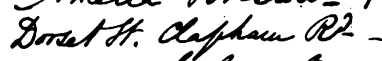

manies, Betriban hing -

Reans henlt reyspow -

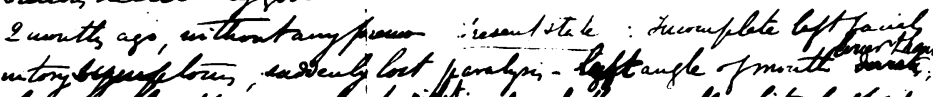

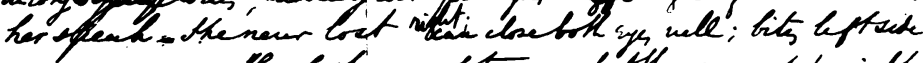

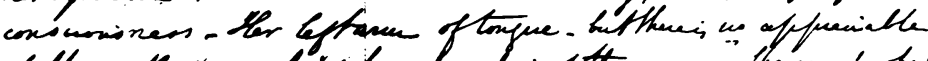

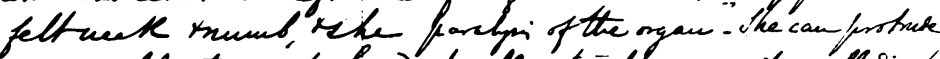

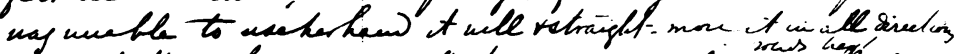

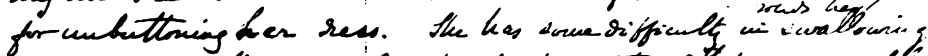

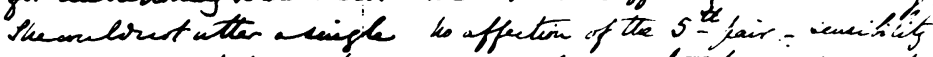

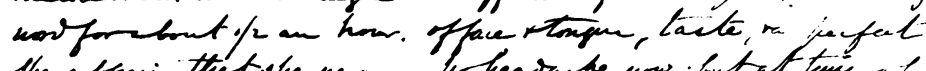

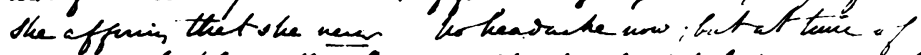

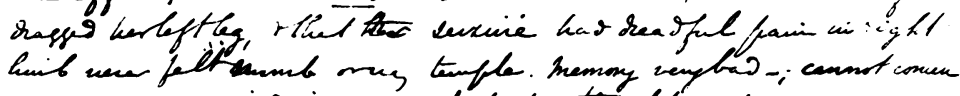

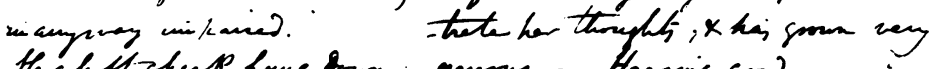

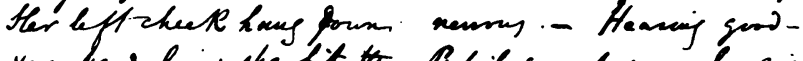

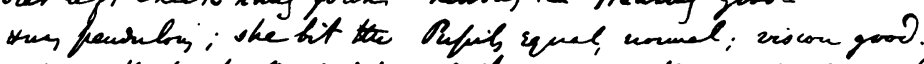

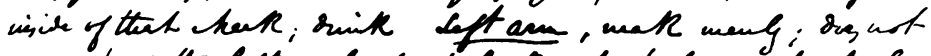

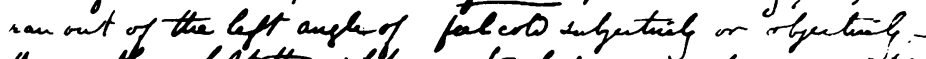

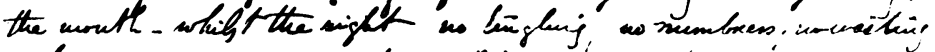

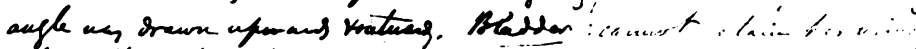

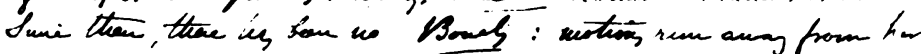

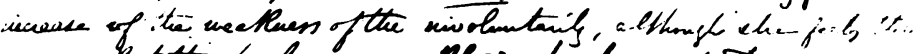

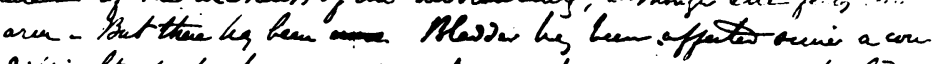

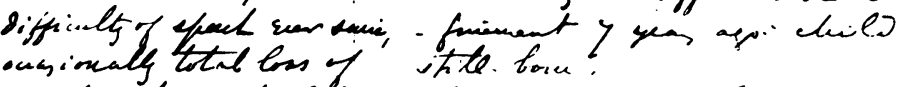
seent. nt of artienclation

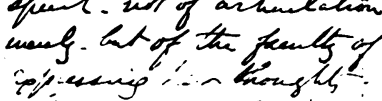

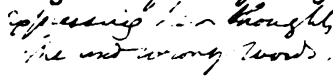
loup, that is bageng towal she was

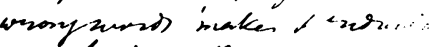

FIG. 1 (a) and (b).-Case notes. of a patient with aphasie and left hemiplegia under the care of Dr. Ramskif with Dr. Hughlings Jackson's pencilled request see her, 1865.

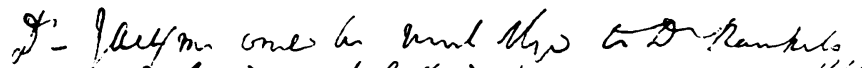

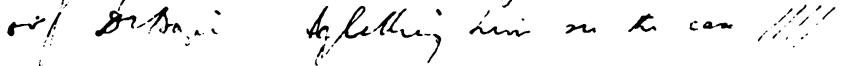

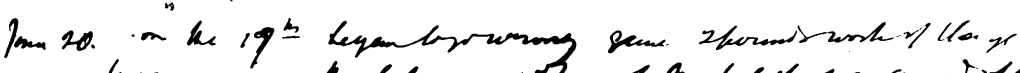

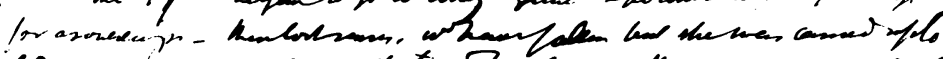

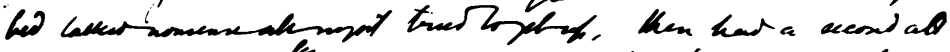

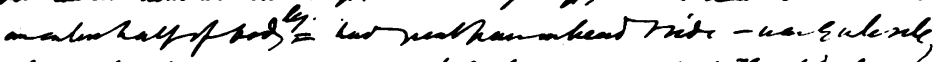

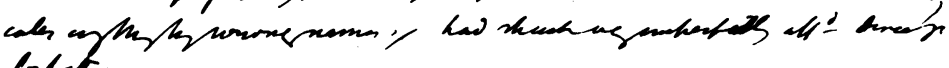
pouts,

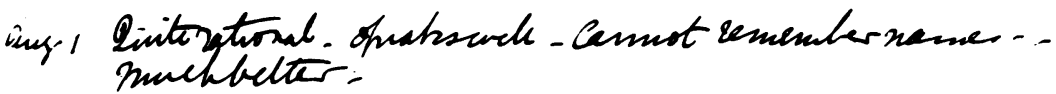

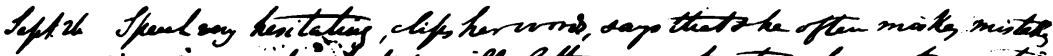

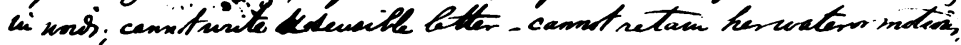
ke, lath fellingervory.

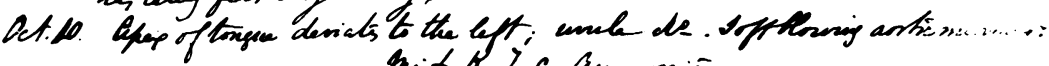
hist. R.d.' c. Aummir 
daily clinical use. The average height of the volumes is 11 inches and the total length of shelf space they occupy up to the year 1946 (when a modern registry was started in which notes are kept unbound) is approximately 860 feet.

On reading the notes one is immediately impressed by the marked similarity between their style and manner of recording the history and that of modern ones. There is the same emphasis on the details of the presenting symptoms.

\section{History Taking}

This is well seen in the notes of a 41-year-old man under the care of Dr. Hughlings Jackson from October, 1878, to February, 1879, who had a right hemiplegia and aphasia resulting from a cerebrovascular accident. After an account of his social, medical, and family history, and a note that he was right-handed, his illness as reported by his wife was recorded as follows:

"September 10th, 1878, he came home from work about 7 a.m., having left about 15 minutes before. He said 'he had a dreadful pain in his head, and that he had felt something burst there as he stooped to open the door'... All of that day and until September 18th the pain continued 'spreading over the whole of his head, in his eyes and across both shoulders'. During the interval between September 10th and 18th he kept to his bed and at times 'seemed delirious'. At times he was perfectly sensible and would answer correctly and at other times she could not understand what he meant. The periods of incorrect and wondering conversation were longer towards the end of the week ... The 7th night after the headaches commenced he was talking all night about 'jumping up on the
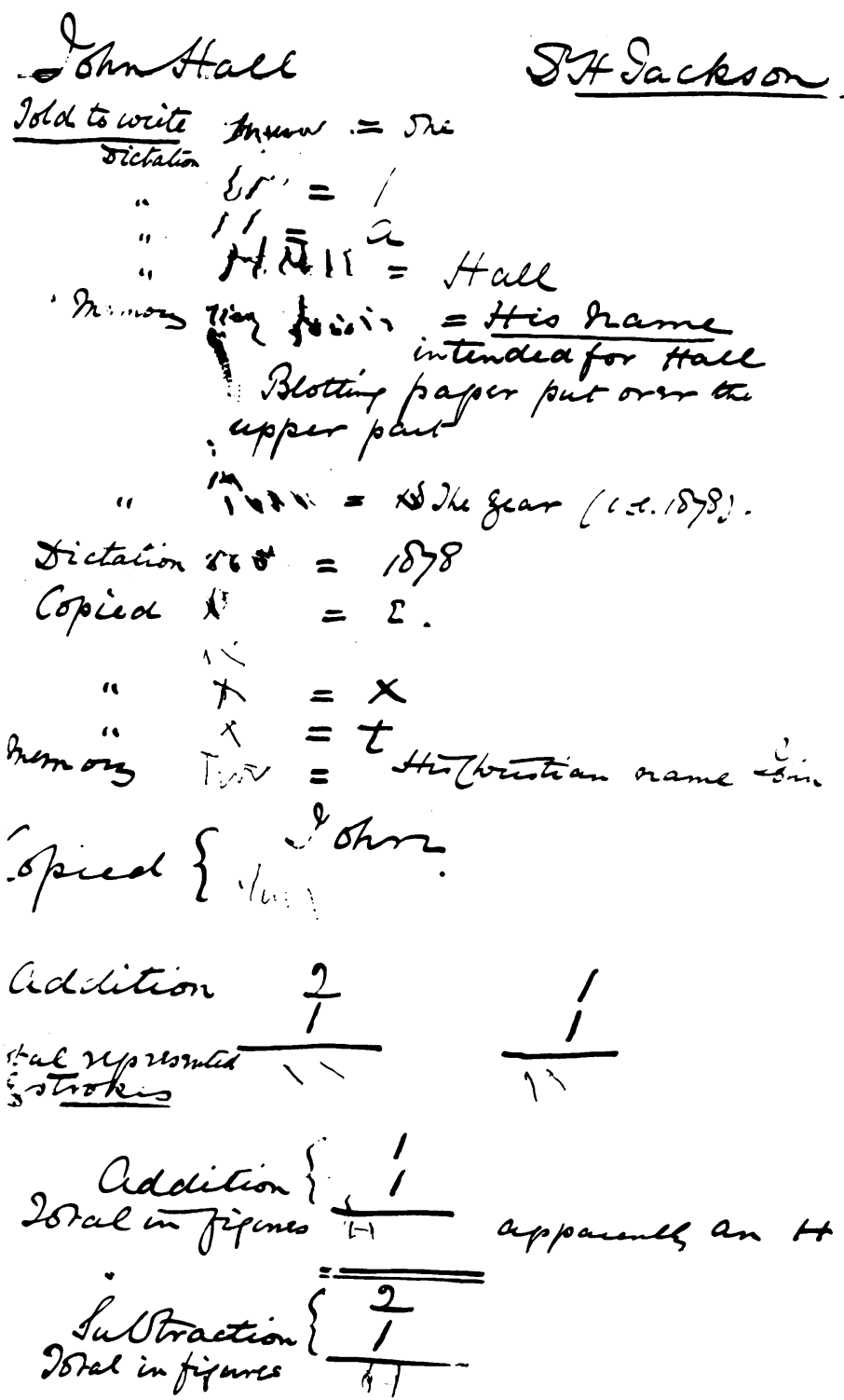

FIG. 3.-Page from case notes of a patient of Dr. Hughlings Jackson showing part of the examination for aphasia, 1878. trucks' and 'paving roads'. On September 18th about 7.45 a.m. his wife could not understand him as he stammered and mumbled. He kept looking at his right hand and rubbing it. He got up at 9.30, dressed and walked into the kitchen perfectly well, turned round and walked back to his bedroom. He sat down and seemed 'to be getting very strange'. His wife undressed him and noticed he seemed to be powerless in his right arm and hand. After going to bed the only thing he said was 'yes' which he said distinctly, the next day he did not say it quite so distinctly. His wife noticed that he kept his left hand always on his forehead, as if in pain."

\section{Aphasia}

Figure 3 shows part of the detail covering many pages with which his aphasia was tested. The notes of 23 November are also of interest in this connexion: 
"On the morning of the 21st the Patient attended a concert in the hospital. The first item in the programme was 'God save the Queen'. Next morning after breakfast, while in bed, he was heard mumbling 'God save the Queen' and kept sufficiently to the tune to attract the attention of the attendant who was in the next room. The other patients, epileptic boys, recognized what he was trying to sing. They then joined in with him and appeared to assist him. He kept it up for quite 15 minutes. The words were not perfectly distinct: something like 'Govsavakeen'. Later on the Resident Medical Officer tried to get him to repeat it. He distinctly said 'Save' but could not get out any tune."

The hospital concert just alluded to was one of the regular performances which were sponsored by voluntary workers. Figure 4 shows a representative programme held as part of the "Course of Winter Entertainments for In-patients" in 1874.

Recorded for posterity in the case notes of the same patient is one of Jackson's most pertinent clinical observations relating to respiratory movements in hemiplegia: "The right side of the chest in all parts moves more than the left on quiet breathing; the shoulder rises more on the right, the right lower ribs invert more, the costal angle formed by them is at all times higher. There is, however, more breathing on the left". This manuscript note anticipated by 17 years Jackson's printed account of the difference in hemiplegics between "voluntary" and "involuntary" expansion of the chest (see Lancet, $1895,1,476$ ), an example of the value of original rather than printed sources for tracing the development of neurological ideas.

\section{Diagnosis}

Although it is surprising how many pre-1900 diagnoses conform to modern concepts, some of course do not. For instance, a 4-year-old boy under the care of Sir David Ferrier in 1890, who was discharged improved after one month, had an eight weeks' history of illness beginning "when he dropped a glass bottle which broke and gave him a fright and this seemed to stupify him so that he remained rooted for 2 to 3 minutes. When removed he began to cry and would touch no food." On examination he was reported to be "drowsy, fretful, and peevish". The nurses reported that "he is stupid and extremely stubborn". No further details are given and there is not sufficient evidence to speculate on which of a number of more serious conditions he may have suffered from. One must therefore rest content with the diagnosis made at the time, which was simply "obstinacy".

Hysteria and epilepsy were not as sharply differentiated as they are today, and fits which are recognizably epileptic were described as hysterical or "hysteroid", especially those accompanied by auto $\overline{\mathbb{Q}}$ matic and other strange behaviour but without the characteristics of grand mal. Many notes of epileption

\section{National Hospital for the Paralysed and Epileptic, \\ 23 \& 24, QUEEN SQUARE, BLOOMSBURY.}

Course of Winter Entertamments tor In-Patients, $1873-1874$.

(BEING THE PIFTH ANNUAL COURSE.)

EXTRA EVENING-THURSDAY, APRIL I6/, 1874.

The Chair will be taken by E. H. CHANDLER, Esq., Hon. Sec. $A$ Grand Séance Fantastique

Magic, Illusions, ${ }^{\circ}$ Necromancy, \&c.,

MONSIEUR EVANION,

The Royal Illusionist, Humourist, \&c.

(. Is performed before their Rogral Highmesses the Prince and Primiess of Wales, if Sandringham, Oct. 27 th, 1860.

PART I.

INTRODUCTION “Coronation March" (Prophète) .. Mejerlecr. Miss MrRricx.

PART SONG _... “Sir Knight, Sir Knight ” ... ... Pearson.

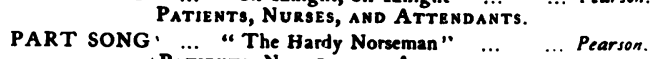
Patients, Nurses, amd Attrendants.

Novel Series of Illusive and Amusing Eastern and European Recreatiun 1. - C A G L I O S T R O'S C L O C K, $A$ wonderful piece of mechanism.

In which M. Evanion will perform oome of the most extraordinary Tours diddre se ...

Unanimously declared to be the most inexplicable illusion, 4.-THE FLORAL WONDER,

5.-EGYPTIAN NECROMANCY, A curious operation and unrivalled performance.
6.-LA BOUGIE CABALISTIQUE, 6.- LA BOUGIE CABALISTIQUE 7.-THE ARABESQUE RINGS, 7.- A peculiar and surprising performance.

$A N, I N T E R V A L$ OF TEN MINUTES. PART II.

INTRODUCTORY OVERTURE-Pianoforte ... MISs MERRILK PART SONG ... "My Love has Gone to Battle" ... Kucken. PART SONG ... "Sleep, Gentle Flower " $\quad \ldots \quad$ H. Leslie.

8.-LE MONNAYAGE MYSTERIEUSE, Interescing Feats of Dexterity and Manipulations.

A masterpiece of skill, which cannot fail to astonish oven the most kn'swing. 10.-LES EVENTAILS JAPON, I 1. L E S M E T A M O R P H O S E S,

The previous explanation of which would diminish the surprise of the spectatur 13.-LE CHAPEAU SANS FIN,

14.-EVANION'S NEW \& WONDERFUL FLAG FEAT, Multifarious production of thousends of Banners of all Nations.

Deors open for Visitors at Half-past Six; to Commence punctually at Sirzers: -Clock, and to Conclude at Nine.

FIG. 4.-Programme of a concert for the patients, 1874 . 
patients contain detailed descriptions of fits witnessed by the nursing staff, whose observations regularly included testing of pupillary responses and limb reflexes. The following is an example of a nurse's note from the year 1888:

"3 p.m. Patient was sitting by the fire in the Day Room. He suddenly covered his face with his hands, made a loud noise in his throat and fell to the right; the limbs were quickly drawn up, right side first then the left. $\mathrm{He}$ was very rigid and quite unconscious; the head and eyes were turned to right, face flushed, eyes blinking, pupils dilated; he remained in this condition for about a minute until the limbs relaxed. He then lay struggling and kicking on the floor for about three minutes and continued trying to get up. When he did so he staggered about in a half conscious state muttering different words and sentences. Knee jerks were present during and after fit. Ankle jerks were present during and after fit. Ankle clonus absent during and after fit. Passed water. Did not bite his tongue. Face was flushed all through the attack. Pupils did not become normal till after the fit."

The term "functional" was frequently used in such a context as "functional paralysis" to describe diseases of the nervous system without permanent structural change, as in paralysis with recovery in patients with disseminated sclerosis. This is different from the less exact sense in which it is used today implying a psychogenic rather than an organic origin of symptoms. Such changes in the meaning of terms still in use must be borne in mind in assessing old clinical records.

\section{Medical and Surgical Treatment}

There was nothing remarkable in the medical treatment administered at the National Hospital for the period under review. Baths of all kinds came in early as well as physiotherapy. Indeed, physiotherapy and various kinds of electrical treatment were the treatments given in the hospital which received most comment in both the medical and the lay press.

Figure 5 shows a cutting from a newspaper of about 1868 preserved in the hospital scrapbook describing the new wards having the unique feature that to each was attached a day room, the "electrical room", and "a congeries of baths, in every variety". Sulphur baths seem to have been especially favoured in cases of general paralysis of the insane. In 1879 a patient of Dr. Bastian undoubtedly suffering from G.P.I. was discharged after six months' "much improved" following a course of sulphur baths, evidence of the improvement being recorded in serial samples of his handwriting. The writer of his notespresumably the house physician-concluded: "it may be imagination, but he seemed to improve as

\section{NATIONAL HOSPITAL FOR THE PARALYSED AND EPILEPTIC.}

Yesterday wes a day to be marked in the history of thin institution, inasmuch as its scheme of operations wes onlarged by the formal opening of additional wand for patients. For this occasion the ingular epectaclo wae exhibited of a hospital en fete. There was, in fact, a sort of celebration, for which the whole building was put into - state of ornamentation, and proceedings of a varied character were carried on from one o'clock in the day until after eight in the evening. In the firet place, there was an eloction of five pensioners; for it is a pecu. liarity of this institution that it has a fund for granting annuities to paralysed or epileptic pernons, of the value of $£ 15$ and $£ 10$. Then came an assemblage of the nume. rous visitors in the ont-patients' spacious waiting-room, and addresses illuatrative of the objects and progress of the hospital were delivered by Mr. Alderman Hale, chair. man of the board of mauagement, and Mr. E. H. Chandler, the-honorary socretary. A special thanksgiving eervice was then performed by the Rev. J. Buck, rector of St. Georgo the Martyr; the Rev. Gerald Lndlor Hallett, chaplain of the hospital; and enother clergyman. A procession then formed, that marched to the new wards, whieh were formally opened by the Rev. Mr. Buck. The visitar then dippersed over the building, exmining the whole establinhment. Here therefore it may well be stated that the hompital was founded in 1859 , at the suggestion and chiefl J through the agency of Mr. Chandler and his sisters, for the treatment and relief of paralysis, epilepsy, and other diseases of the nervous system, and it found a local habitation in two houses, 24 and 25, Queen-square, Bloomsbury, where the plin was carried on in the cases of both out and in patients, the former being very nnmerous, under tho auspices of a most skilful medical staff. In 1865 it was thought desirable to enlarge and reconstruct the build. ing; and this has been done on a plan of great convenieuce and perfection of arrangement. It should be said that there is connected with the establishment a ladies' committee, the member of which are indefatigable in their exertions, and it is by their efforts alone that the large sum of $\$ 6,000$ wass raised which has been devoted to making the hospital one of the most comfortable kind. In many of ito features it is unique. Thus to each ward is attached a day room, comfortably, and even elegantly. fitted up; while the dormitories are models of cleanliness, diriness, and convenience. Amongat the medical appliances is an electrical room, in which machines of every description and power are brought together. Then there was opened yesterday quite a congeries of baths, in every variety, sulphur, douohe, vitz, vapour, and, last but not least, a needle bath, which is : Russian in vention. As adjuncts to the curative processes, there are gymnacis attached to both the male and female wards, while therte is a garden in which air and exercise may bo taken bo the patients, to facilitate which every varisty of wheel chuir is to be found on the premises. The frout af the building is appropriated to female patients ; whilo tho males are acconmodated in a separate structure at the beok, whiah is approached by a corridor. Up to the mesent time no fower than 8,000 out-patients hare bean trealod and there are now 1,000 on the books. In the bospitul bitherto there have been received 80 patiouts; they opening of the new wards will enable - canumodation to bo afiorded to 60. Observation or the system pursued in thin hospital can lead to no other opinion than that it is in overy way a most useful charity, is well managed (it is entiraly free from debt), and is in every respect worthy of support from the public.

FIG. 5.-Newspaper cutting describing the new wards about 1868 , 
long as he took Sulphur Baths, and he rapidly deteriorated during the fortnight while the boilers were being cleaned and Sulphur Baths were necessarily discontinued". "However," he added with that honesty of observation which is apparent in all the notes, "it must be observed that during the same fortnight he was without the Iodide of Potassium".

Counterirritation was much used and ice bags to the spine was a favourite treatment for paraplegia but no particular benefit was noted. Other treatments such as galvanic and faradic currents and hypnosis were, of course, also used. For instance, another patient of Dr. Bastian in 1888 suffering "from functional contracture and anaesthesia of the right arm following an injury at work" was treated with the "strongest galvanic current given for some time without causing the hand to open". Next he was hypnotised by Dr. Beevor who had been a pupil of Charcot in Paris and had produced a testimonial from Charcot in support of his application to the staff of the hospital. However, the only result was to make him "stupid at the time and during the evening". He was hypnotised twice more and each time became "quite unconscious but was not open to suggestions". After the sessions he had "typical hysteroid convulsions". Next he was "put under the ether": his hand relaxed when he lost consciousness but contracted again when he came round. The "actual cautery" was then applied on several occasions, "the only effect" being that he "resented its application". Finally, after three months of various other treatments he was discharged "unchanged".

From time to time outside doctors were also brought in, such as C. L. Tuckey, an eminent London hypnotist, author of Psycho-therapeutics (1889) who in 1897 treated a patient of Sir David Ferrier suffering from hysterical paraplegia by suggesting "that he should walk well, with a favourable result".

Some account of the operative treatment practised in the National Hospital during the early days was given by Jefferson in his Victor Horsley centenary lecture (Brit. med. J., 1957, 1, 903). The first craniotomy was performed in the hospital in 1886; the first successful operation for removal of a spinal cord tumour in 1887; and the first carotid ligation in 1889 on a 39 -year-old man who had come to the National Hospital from California, U.S.A., complaining of severe persistent headaches which were tentatively diagnosed as being due to an intracranial aneurysm. Among the many interesting features of his notes are the detailed records kept by Marcus Gunn, ophthalmic surgeon to the hospital. They contain the first observations on the effect of orbital and carotid compression on the retinal blood vessels. On March 11, 1889, Gunn wrote to Siro Victor Horsley: "I saw the 'carotid man' again on Friday ... There is no doubt that at the operation, compression of the common carotid was followed after a short interval by a slight diminution in thes size of the retinal veins but they seemed again to increase to the normal size while the compression was kept up. No change could be noted in the arteries, probably on account of their really shrunkens? condition so the amount of blood entering the resto of the vessels could be best gauged by the size of theo veins. On ligature of the artery a similar slight㱒 temporary diminution in size of the retinal veins $\frac{\mathbb{Q}}{\Omega}$ was observed. On the third day after ligature then veins of the right retina had regained their larges size noticed before the operation and in fact were. of the same apparent size as noted about a minute $\vec{\overrightarrow{ }}$ or so after the first ligatures. It was now found that light digital pressure on that globe did not evoke the marked arterial pulse observed previously to theo operation. A considerably firmer pressure wasi necessary to do this."

The first ligation failed to produce lasting relief $\dot{\infty}$ and for reasons which are not clear ligation was also $v$ performed on the other side. Not surprisingly a을 significant degree of dementia resulted. The patient developed "a great scheme by which he is to make 3 his fortune and give employment to thousands young men" by setting them "to sell bibles at a cleggr $\overrightarrow{0}$ profit of 5 dollars" in all the towns and cities of? America-and "what can be done with Bibles, can be done with other things". He abused "Mr. Horsley, Dr. Ferrier, the H.P.s and nurses. Threw a flower-pot through the window today and smashedo the glass. When asked why he did it he said 'inळ order to get fresh air'. Also threw a cup of tea $\underset{\vec{F}}{\stackrel{2}{ }}$ against the wall because he said it was 'swipes' and $\overrightarrow{0}$ not proper tea. Refuses to take medicine that is ordered for him, and would not take an aperient though bowels had not acted for a week. Slept with his clothes on several nights; nothing would induce him to undress. Said it made him feel as if he were? sleeping out in the forests of America."

Trephining, the oldest operation of which medicine has factual evidence, was of course a not infrequento procedure after Horsley's appointment to the staff in 1886 , as well as exploration of the spine and 음 decompression for spinal caries.

\section{Pathology}

Post-mortem examinations were performed and \% recorded in the notes from the mid-1860s but became $N$ more detailed over the years and by 1888 included $N_{\omega}^{N}$ microscopic examination of tumours.

Figure 6 shows the out-patient sheet of a 22-year-o 


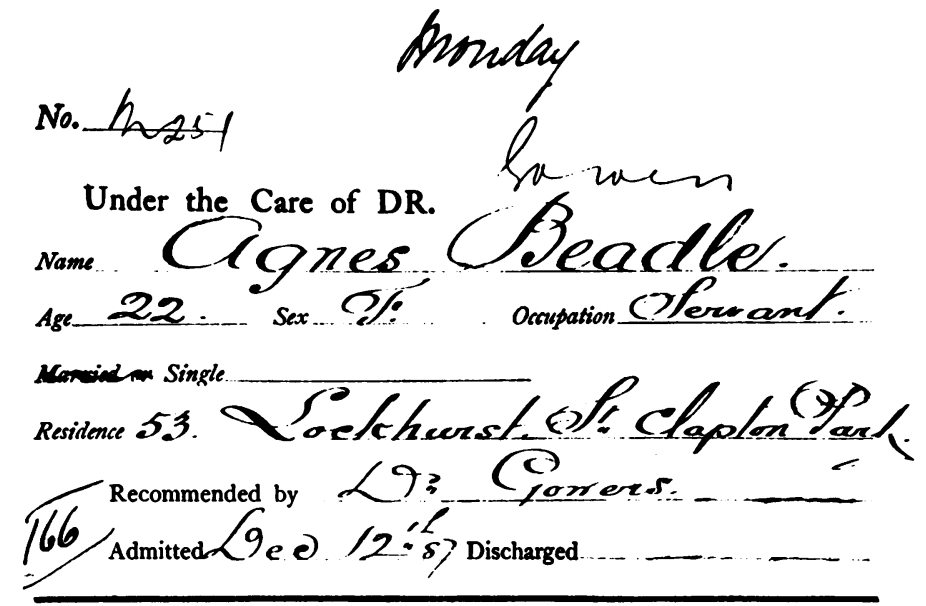

\section{A S E.}

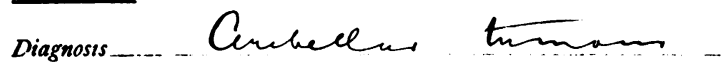

Durationi

Family Histery_-

Previous Health Nadhine eale lacts

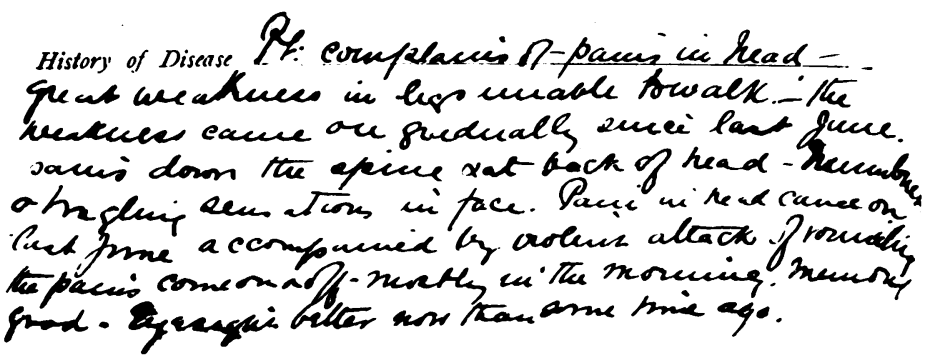

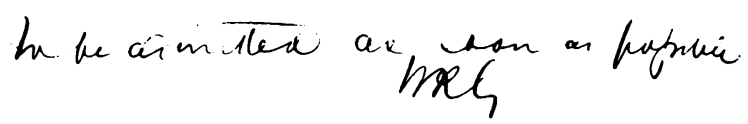

FIG. 6.-Out-patient sheet with diagnosis "cerebellar tumour" and "to be admitted as soon as possible, W.R.G." in the hand of Sir William Gowers, 1887.

old woman admitted in December, 1887 , who died in the hospital in April the following year. Note the readiness with which Sir William $\mathbf{R}$. Gowers diagnosed a cerebellar tumour at his first examination of the patient recorded at the bottom of the sheet in his own hand, signed W.R.G.

Figure 7 shows what appear to be Gowers' own drawings of the post-mortem findings when the tumour was located in the upper midbrain pressing on the left lobe of the cerebellum. On the right are shown a number of tumour cells and for comparison some red blood cells; below them a section of one suprarenal gland which the post-mortem report suggests was atrophic and caseous.

\section{The Neurological Examination}

Of great interest to the clinician is the development of case taking and examination to its present- 


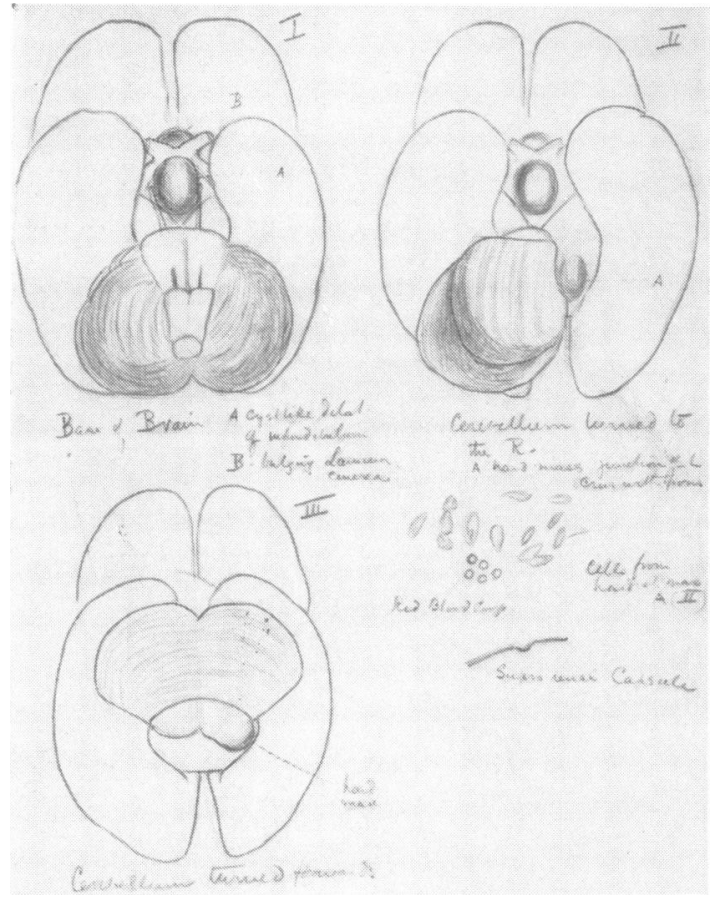

FIG. 7.-Drawings of post-mortem findings in the patient whose outpatient sheet is shown in Fig. 6, probably made by Gowers himself, 1888 .

day form as it emerges from a study of these case notes. In the beginning the chief emphasis was placed on the history of the illness and only gross physical abnormalities were recorded. Thereafter, the modern scheme of case taking gradually evolved. By January, 1875, the notes of a patient of Dr. Ramskill were written in the order: family history, social history, previous illnesses, history of present illnesses, on examination, beginning with general physical examination followed by mental state, cranial nerves, spinal nerves, electrical reactions to faradism and galvanism, limb measurements, and finally urine examination. Examination of the extremities was divided into motion and sensation. Hand grip was measured and compared by a dyanometer.

The use of the aesthesiometer for measuring twopoint discrimination and examination for tactile localization is also first recorded in 1875, and perimetry charts became general in patients who had visual field defects. In the same year detailed observations for nystagmus, including what is now referred to as the ataxic form, were made and pupil- lary responses to light first mentioned. Sphygmographic tracings of the brachial and radial pulses $\bar{O}$ were occasionally taken as early as 1878 .

Ophthalmoscopy by the indirect method wase generally performed by 1870 , papilloedema being ${ }_{\infty}$ referred to as optic neuritis. High skill was shown, as for instance when in May, 1878, Dr. Thomas Buzzard recorded seeing what was doubtless choroidal tubercle "about the distance of a pea to: the upper and outer part of the disc there is a rounded yellowish white patch about the size of a음 small pea". Dr. Jackson also examined the fundus and confirmed Buzzard's finding. The patient $\overline{\overline{\bar{S}}}$ subsequently died of tuberculous meningitis con- $\bar{\nabla}$ firmed at necropsy.

Pupillary reaction on accommodation was first $\stackrel{0}{\omega}$ recorded in 1878 in a patient of Dr. Hughlings. Jackson, who was also observed to have absent $\vec{A}$ pupillary reflexes to light. However, the name of Argyll Robertson who had described these phenomena in 1869 does not appear. The patient had lightning or "electricity pains" and absent "patellaĩ jerks", and the diagnosis of locomotor ataxy was made. Two years later in 1880 reflex dilatation of $\rightarrow$ the pupils to painful stimuli was first recorded in another of Jackson's patients.

By 1878 cutaneous and deep tendon reflexes weyetested in all patients and ankle clonus was recorded. In June, 1880, a patient with a right hemiplegia wiâs: noted to have "deficient cutaneous reflexes on the $\overrightarrow{0}$ right side" which included testing of abdominal and cremasteric responses. The skin plantar responses were recorded from 1870 but represented reflex with-은 drawal of the leg on stimulation of the sole. The plantar response in terms of flexion and extension of the big toe and its significance-described by음 Babinski in 1896-was first recorded in the hospital notes in 1899 when Drs. Collier and Bramwell were $\overline{\bar{O}}$ house physicians.

\section{Summary}

This brief view of the case notes of the National Hospital, Queen Square, shows that by 1880 there? had developed a scheme of history taking and examination which approximates to that of today, with the exception only of special investigations. These notes and those of the many other physicians to the hospital formed the basis of the contributiono of "Queen Square" to the growing science of neuro- $>$ logy: precise, detailed, and unbiased observation of으․ clinical facts recorded in a lively, descriptive style.

We thank the Medical Committee of the National Hospital, Queen Square, for permission to publish. 